\title{
Leitura multimodal e o processo de construção de sentido em charges
}

\section{Lectura multimodal y el proceso de construcción de sentido en viñetas}

\author{
Liviane da Silva Martins ${ }^{1}$
}

DOI: $10.28998 / 2317-9945.2020 n 65 p 10-23$

\section{Resumo}

Textos multimodais são aqueles compostos por mais de um modo semiótico que se integram na construção de sentido do texto e se fazem presentes no nosso dia a dia, como os textos publicitários, as historinhas e as charges. O objetivo deste artigo é mostrar o processo de construção de sentido nas charges através da leitura multimodal e para isso discutimos questões sobre a multimodalidade e sua contribuição para a compreensão textual baseados nos estudos de Kress e van Leeuwen (2002; 2006), Jewitt (2005), Coscarelli e Novais (2010), Kress (2010), entre outros. Selecionamos três charges para análise seguindo dois critérios estabelecidos: a temática do meio ambiente e a presença tanto da linguagem verbal quanto da imagem. A metodologia adotada foi qualitativa e descritiva, em que os elementos multimodais das charges foram identificados e analisados. Foram observados os seguintes elementos multimodais: cor, participantes representados, olhar, relação entre os participantes, saliência, enquadramento e relação entre texto verbal e imagem. Concluimos que a construção da crítica e ironia tão marcantes desse gênero textual foram alcançadas pela contribuição de cada um dos elementos multimodais integrados entre si.

Palavras-chave: Multimodalidade. Leitura. Charge. Construção de sentido

\section{Resumen}

Los textos multimodales son aquellos compuestos por más de una forma semiótica que se integran en la construcción del significado del texto y están presentes en nuestro cotidiano, como los textos publicitarios, las historietas y las viñetas. El objetivo de este trabajo es mostrar el proceso de construcción de significado en las vinetas a través de la lectura multimodal y para ello discutimos cuestiones sobre la multimodalidad y su contribución a la comprensión textual basada en los estudios de Kress y van Leeuwen (2002; 2006), Jewitt (2005), Coscarelli y Novais (2010), Kress (2010), entre otros. Seleccionamos tres viñetas para el análisis siguiendo dos criterios establecidos: el tema del medio ambiente y la presencia de lenguaje verbal e imagen. La metodología adoptada fue cualitativa y descriptiva, donde se identificaron y analizaron los elementos multimodales de las viñetas. Se observaron los siguientes elementos multimodales: color, participantes representados, la mirada, relación entre participantes, elemento sobresaliente, encuadre y relación entre texto verbal e imagen. Llegamos a la conclusión de que la construcción de la crítica y la ironía tan característicos en este género textual se logró mediante la contribución de cada uno de los elementos multimodales integrados entre sí.

Palabras clave: Multimodalidad. Lectura. Viñeta. Construcción de sentido

Recebido em: 25/08/2019.

Aceito em: 21/10/2019.

\footnotetext{
${ }^{1}$ Mestranda em Letras na Universidade Estadual do Piauí. Professora do Instituto Federal do Piauí.
} 


\section{Introdução}

Diariamente convivemos e usamos tecnologias distintas que nos possibilitam a realização de atividades variadas como a da comunicação. Comunicamo-nos de diversas maneiras utilizando modos semióticos diferentes e integrados, como, por exemplo, quando usamos a linguagem oral associada à linguagem gestual ou a linguagem escrita associada à imagem. Essa integração de modos semióticos é o que caracteriza a multimodalidade. Essa temática sempre esteve presente em nossa sociedade, mas nos últimos anos tem ganhado destaque nas pesquisas e discussões acadêmicas.

Dentre os modos semióticos em estudo, um novo olhar tem sido lançado para o papel da imagem, que hoje já é vista, por alguns estudiosos, como um texto repleto de significação. Kress e van Leeuwen, ao lançar a Gramática de Design Visual, em 2006, estimularam mais estudos, debates e pesquisas na área de leitura de imagens e na multimodalidade.

As imagens estão presentes em toda a história da humanidade. Por exemplo, nos tempos primitivos temos a presença das pinturas rupestres: os egípcios registravam seus costumes e cultura em pinturas nas pirâmides; na Europa, as grandes e antigas catedrais apresentam pinturas de cenas bíblicas, que ensinavam mesmo aqueles que não sabiam ler (palavras). Hoje em dia, podemos citar, como exemplo, os grafites expostos nos muros de muitas cidades e os anúncios publicitários vistos nos outdoors, cartazes e na tv. Todas essas imagens são cheias de significação e sua compreensão é alcançada por quem se dispõe a lêlas.

Kress e van Leeuwen (2006) afirmam que todo texto é multimodal, e que imagem também é texto. Outros autores como Jewitt (2005) e Dionísio (2014) também concordam que todo texto é multimodal e que mesmo o texto verbal (aquele que apresenta somente a linguagem verbal) pode apresentar recursos visuais que o caracterizem como multimodal, como o uso de gráficos, tabelas, palavras ou trechos em negrito ou itálico, ou o próprio layout do texto. O texto imagético (aquele composto somente por imagem) apresenta como traços multimodais as cores, a saliência, a disposição dos elementos: no centro ou em periferia, a presença de moldura, o olhar dos participantes ou a perspectiva da imagem. Outro tipo de texto é o verbo-imagético, que é composto pela integração da linguagem verbal e da imagem.

Deparamo-nos com esses textos no nosso dia a dia: são os cartazes de publicidade, os folhetos de supermercado, as tirinhas, os memes, as charges e caricaturas, dentre tantos outros. A leitura desses textos é uma atividade dinâmica que pode levar o leitor a considerar, analisar (mesmo que intuitivamente) e interagir com os modos representados. O reconhecimento da multimodalidade textual conduz a uma nova forma de ler o texto que leva em conta todos os modos que o compõem, é a chamada leitura multimodal como debatida por Jewitt (2005) e Coscarelli e Novais (2010).

Dentre esses textos multimodais, selecionamos para analisar, neste trabalho, a charge, que reúne elementos verbais e imagéticos (sendo que o verbal nem sempre está presente) para fazer uma crítica a algum fato social ou político. A charge é um texto dinâmico, tem caráter interdisciplinar, podendo ser facilmente utilizada na sala de aula, além de despertar no leitor um caráter reflexivo e crítico, como nos mostram Flôres (2002), Carvalho (2006) e Vergueiro e Ramos (2009). 
Considerando esse contexto, este trabalho tem como objetivo mostrar o processo de construção de sentido nas charges, utilizando-se da leitura multimodal a partir das contribuições de Kress e van Leeuwen (2006), Jewitt (2005), Coscarelli e Novais (2010) para a identificação dos modos presentes e como eles colaboram para a construção de sentido nas charges. Para alcançar tal objetivo, analisamos três charges relacionadas à temática sobre o meio ambiente, selecionadas em um site de domínio público. Dessa forma, iniciamos este trabalho explicando, de maneira geral, as questões que envolvem a multimodalidade e a leitura multimodal. Em seguida, fazemos uma breve explicação sobre o gênero charge, finalizando com a análise multimodal proposta.

\section{Abordando brevemente a multimodalidade}

O termo multimodalidade foi estudado mais intensamente por Kress e van Leeuwen na década de 90. Baseados na gramática sistêmico-funcional de Halliday, os estudiosos lançaram a Gramática de Design Visual, em 1996, explorando as metafunções da linguagem não mais no texto verbal e sim nas imagens. Essas passaram a ser vistas não apenas como ilustrações, mas como um texto repleto de informações e significado.

A evolução tecnológica permitiu ao homem inovar suas formas de comunicação integrando diversos modos que são usados em harmonia na elaboração dos mais variados textos, manifestados nos gêneros textuais, muitos comuns a todos por fazerem parte do dia a dia de cada um. Modos como a linguagem verbal e a visual estão mais presentes nos textos que nos acompanham diariamente, como os panfletos, os folhetos de lojas e supermercados, cartazes de publicidade, propagandas e avisos. Alguns deles nem precisam de uma parte verbal para que sua intenção seja reconhecida, uma imagem por si só pode transmitir toda uma informação compreensível para o leitor. Um exemplo comum encontrado nos jornais são as caricaturas. Nelas, o olhar, a posição dos participantes ali representados, os gestos, as cores, o ambiente, tudo tem um significado que é compreendido por aqueles que reconhecem o tema abordado na caricatura.

Essa integração entre os diversos modos para compor um único sentido é o que define e caracteriza a multimodalidade. $\mathrm{O}$ texto cujo significado se dê pela composição e interação de mais de um código semiótico é aquele tido como multimodal (KRESS, VAN LEEUWEN, 2006; JEWITT, 2005; KRESS, 2010; DIONÍSIO, 2014). A multimodalidade faz parte de toda forma de comunicação, pois além da linguagem verbal e das imagens, os gestos, a língua oral, os objetos em 3D, som, linhas, cores, entonação, ritmos, melodia também são considerados modos ou recursos semióticos (KRESS, 2010; DIONISIO, 2014).

O modo semiótico (ou signo) não apresenta um significado fixo, em cada contexto em que está inserido ele pode apresentar significados diversos. Kress (2010) esclarece que um signo tem efeito e é compreensível em uma situação, mas pode não sê-lo em situação similar, pois ele é particular a cada momento, a cada situação e é compreendido por aqueles que dela fazem parte. Assim, conhecer o contexto em que uma situação ocorre facilitará sua compreensão. Isso marca também as diferentes representações que culturas diversas podem realizar sobre um mesmo fenômeno, em que cada uma se utilizará de recursos que lhe são próprios.

Os modos semióticos são considerados como um produto social (KRESS, 2010), 
gerado pelas escolhas dos modos existentes, sendo realizadas por um indivíduo (ou um grupo) pertencente a uma comunidade e influenciados pela mídia. Acerca dessa produção multimodal pelos membros de uma comunidade, Barbosa, Araújo e Aragão (2016, p. 627) esclarecem que:

aspectos como reprodução ou originalidade, acessibilidade, concepções ou ideias precisam ser articulados e interpretados, ainda que isso não signifique que interpretações sejam únicas, uma vez que, mesmo sendo de uma mesma comunidade, indivíduos podem ter experiências diferentes que levem a interpretações diferentes (BARBOSA; ARAÚJO; ARAGÃO, 2016, p. 627).

O contexto pessoal de cada leitor e o situacional podem ser influenciadores para essas possibilidades de interpretação. O letramento visual da população torna-se necessário pela forte presença dos recursos visuais nas ações diárias. Assim, ela poderá ler, interpretar e produzir esses recursos. Essa interação da população com os diversos recursos visuais pode ser observada no uso constante das redes sociais, em aplicativos de interação social e outras tecnologias digitais em que as pessoas já fazem uso dos recursos visuais, como responder alguém usando emojis ou outras imagens.

Portanto, a multimodalidade se faz presente em todos os textos, isso confirma o que Kress e Van Leewen (2006) e Dionisio (2014) afirmam em seus trabalhos: todo texto é multimodal. Até mesmo aqueles que usam a linguagem verbal e não apresentam imagens são multimodais, pois o layout, as marcações no texto, como palavras ou expressões em negrito ou itálico e o uso de gráficos, por exemplo, também são modos que colaboram para a construção de sentido.

Muitos textos que se popularizam mais facilmente hoje em dia utilizam linguagem verbal e imagética, como os memes, charges, tirinhas, anúncios publicitários e campanhas sócio-educativas. Eles apresentam os mais diversos objetivos e levam o leitor a posicionarse criticamente perante ele, apresentando, assim, uma nova postura que comunga com a sociedade atual, cada dia mais visual.

Barbosa, Santos e Oliveira (2012) afirmam que os textos multimodais se apresentam cheios de valores ideológicos, e por isso as práticas de letramento (leitura e escrita) levam o sujeito a ter uma postura de discernimento, de questionamento e de consciência crítica perante as imagens que está lendo, por consequência, argumentando e se posicionando diante do que lê.

Esse posicionamento e os argumentos que o sujeito utiliza ao interpretar um texto multimodal são influenciados pela visão do leitor sobre o texto. Os modos que o leitor consegue identificar, a escolha da ordem de leitura desses modos (pois nos textos visuais não há linearidade na leitura), e os significados que eles produzem dependem do conhecimento linguístico, do conhecimento de mundo, da sociedade e da cultura em que está inserido.

\section{A competência leitora e a leitura multimodal}

Ao realizar a leitura, o leitor se posiciona diante do texto com objetivos previamente estabelecidos (na mente) como, por exemplo, ver o texto com a finalidade de 
se entreter, informar ou aprender. Isso lhe permite selecionar o que vai ler dentro de uma ampla variedade textual, bem como se posicionar diante do que lê e da sociedade da qual faz parte. Rojo (2002) comenta sobre o comportamento do leitor ao ter contato com o texto e afirma que:

a partir da situação de leitura, de suas finalidades, da esfera de comunicação em que ela se dá; do suporte do texto (livro, jornal, revista, outdoor etc.); de sua disposição na página; de seu título, de fotos, legendas e ilustrações, o leitor levanta hipóteses tanto sobre o conteúdo como sobre a forma do texto ou da porção seguinte de texto que estará lendo (ROJO, 2002, p. 5).

As hipóteses levantadas auxiliarão o leitor na compreensão do texto e em seu posicionamento diante dele. Ele poderá resgatar o que conhece sobre o tema (caso conheça algo a respeito), confirmar as hipóteses, refutá-las, concordar, discordar ou simplesmente aceitar as informações lidas.

Cassany (2009) nos aponta que hoje lemos de maneira mais diversificada, utilizamos os mais variados suportes, nos mais variados idiomas e com multimodalidade, sendo a leitura um ato complexo por reunir o processamento do texto, a recuperação de inferências e ainda por conseguir construir um significado coerente. $\mathrm{O}$ conhecimento adquirido por uma leitura crítica permite que o leitor saiba se posicionar nas mais diversas situações do cotidiano. A variedade textual e as características que possuem nos mostram que a forma de ler o texto vem sofrendo alterações, pois não se lê de forma rígida, mas de forma interativa, adequando-se a cada situação (COSCARELLI; NOVAIS, 2010).

Ao ler um texto multimodal se devem considerar os modos e observar os aspectos que o caracterizam, pois são pontos que nos levam a praticar uma nova maneira de ler (JEWITT, 2005) e que auxiliam na construção de sentido do texto. Essa atitude nos leva também a considerar a imagem, quando esta estiver presente, como um texto repleto de informação em si e de elementos que vão contribuir para o sentido da informação ali representada e a observar os recursos visuais presentes também na linguagem verbal. Sobre isso Coscarelli e Novais (2010, p. 39) afirmam que:

no caso de textos multimodais, ou seja, daqueles textos compostos por várias modalidades sígnicas que não só a verbal, o leitor precisa reconhecer outras unidades além do léxico verbal, ou seja, precisa perceber as unidades dessas outras modalidades e integrá-las. Imagem, som, movimento, design são categorias de signos organizadas por elementos de natureza diversa, que precisam ser decodificados em unidades que vão contribuir para a construção do sentido (COSCARELI; NOVAIS, 2010, p. 39).

A informação do texto e seu sentido estão indicados por cada um dos modos presentes no texto (seja oral ou impresso). Cada elemento presente ajuda na construção do sentido porque carrega em si uma informação que deve ser associada às demais. A análise de cada elemento ou modo presente no texto não deve ocorrer de forma isolada, independente dos demais, pois, se isolado, pode possibilitar variadas interpretações e quando analisado em conjunto o significado de cada modo se interrelaciona, contribuindo para o sentido geral do texto.

Ao analisar uma imagem alguns elementos podem ser destacados, como a cor, os 
participantes representados, seu olhar, seu posicionamento na imagem, o enquadramento e a relação que estabelecem entre si e com o leitor. Sobre a cor, Kress e van Leeuwen (2002) afirmam que ela surge na imagem provinda do interesse do produtor, motivada de acordo com seus interesses. Ela transmite intenções, podendo impressionar, intimidar ou alertar (como a cor laranja, por exemplo).

Outros elementos como a saliência, o enquadramento e os participantes representados são explicados por Kress e van Leeuwen (2006). Eles nos mostram que alguns elementos nas imagens podem estar mais em evidência; são os mais salientes. Isso pode ser demonstrado pelo tamanho ou pela luz que incide sobre os elementos, contrastes ou valor tonal que apresentam.

O enquadramento, de acordo com os autores, pode estabelecer uma sensação de identidade do leitor para com a imagem, quando os participantes estão mais próximos a esse leitor, quando a imagem está "fechada" neles. Quando o enquadramento está mais "aberto", a imagem está mais ampla transmite uma sensação de individualidade e distanciamento dos participantes em relação ao leitor.

Em relação aos participantes, que podem ser pessoas, animais ou objetos, se analisa a relação que estabelecem entre si e com o leitor. O olhar deles pode auxiliar na construção do sentido, quando ele é direcionado ao espectador tem-se uma "imagem de demanda" que exige algo do leitor, exige que ele faça algo ou reaja de alguma forma. Quando o olhar não está voltado para o leitor, tem-se uma "imagem de oferta", que oferece o(s) participante(s) representado(s) para ser observado ou contemplado pelo leitor (KRESS; VAN LEEUWEN, 2006).

O reconhecimento da multimodalidade nos textos pode levar o leitor a não mais priorizar (ou focar) a linguagem verbal, pois a imagem e demais modos semióticos são entendidos como parte da informação. Assim, isolar um único modo semiótico pode fazer o leitor não compreender a mensagem em seu sentido completo ou interpretá-la de modo equivocado. Por isso, é necessário que o leitor saiba da importância da integração de todos os modos para a construção do sentido do texto.

Novos textos pedem novas atitudes diante deles. Portanto, como visto, os textos multimodais se caracterizam por exigir do leitor a realização de uma leitura dinâmica. É necessário ler os modos que integram o texto, associados a isso, as motivações que levam à leitura, a consideração do contexto sócio-cultural e das experiências pessoais dos envolvidos com o texto (produtor e leitor) e até mesmo o contexto em que o próprio texto está inserido devem integrar-se durante a leitura.

\section{Charge: um gênero multimodal}

Os meios de comunicação de massa apresentam informações dos mais variados tipos e nos mais variados estilos. Cada texto é produzido levando em conta o objetivo a que se destina para poder ocorrer a seleção dos modos que o irão compor, bem como relacioná-lo ao objetivo e contexto sócio-histórico-cultural ao qual está inserido.

Os jornais são suportes para a manifestação de diferentes gêneros textuais. Entre eles, a charge, o cartum e as tiras cômicas são facilmente encontrados e são os responsáveis 
pela divulgação destes gêneros e até pela criação deles. A compreensão da mensagem desses gêneros exige do leitor algumas habilidades que podem variar de um para outro, mesmo que minimamente.

Desses gêneros, a charge e o cartum apresentam semelhanças significativas entre si, por isso, faz-se necessário marcar uma distinção entre eles. O cartum apresenta humor universal, ingênuo e descomprometido, que brinca com alguma situação do cotidiano. Apresenta certa atemporalidade e constitui-se de um só desenho, podendo ou não apresentar parte verbal escrita (VERGUEIRO; RAMOS, 2009; CARVALHO, 2006).

A charge é marcada também pela presença dos dois modos semióticos integrados ou apenas do imagético. Sobre a imagem, Flôres (2002) diz que ela:

mostra os pormenores caracterizadores de personagens, situações, ambientes, objetos. Os comentários relativos à situação representada aparecem por escrito. Escrita/ilustração integram-se de tal modo que por vezes fica difícil, senão impossível ler uma charge e compreendê- la, sem considerar os dois códigos complementarmente, associando-os à consideração do interdiscurso que se faz presente como memória, dando uma orientação ao sentido num contexto dado - aquele e não outro qualquer (FLÔRES, 2002, p. 14).

Essa definição marca nitidamente o caráter multimodal do gênero ao mencionar que para ter sentido os códigos (modos), presentes no gênero (linguagem verbal e não verbal), devem ser considerados como interdependentes para sua compreensão. Nele se observa o contexto de produção do gênero para saber a que momento histórico ele se refere e o conhecimento do leitor para que a leitura ocorra de modo eficaz. Cavalcanti (2008) acrescenta ainda que:

quanto à forma, a charge representa figuras existentes no mundo real. Assim, caricaturas e símbolos são utilizados e não desenhos lúdicos, fantasiosos. É necessário ter detalhes que forneçam dados suficientes para a compreensão do leitor, tais como a caracterização do ambiente e as marcas simbolizando o tema (CAVALCANTI, 2008, p. 38).

Esses detalhes são identificados como alguns elementos multimodais que fazem parte do gênero e se integram num sistema semiótico. Dito isso, o caráter social do gênero - que objetiva a ironia e a crítica sobre algum fato social, cultural ou político do momento em que a charge foi produzida - é marcado por um caráter temporal. Vergueiro e Ramos (2009) e Carvalho (2006) destacam outras características para o gênero, como a presença do narrador, que pode ser identificada pela presença de alguma informação dentro de um retângulo e a presença de balões com as falas de algum personagem.

\section{Elementos multimodais e a construção de sentido nas charges}

Inicialmente vamos recordar que o objetivo deste trabalho é mostrar o processo de construção de sentidos nas charges através da leitura multimodal, caracterizando este gênero como multimodal e identificando os modos que convergem para a construção de sentido. Assim, a abordagem utilizada para análise do corpus selecionado é qualitativa e descritiva. Para compor este corpus foram selecionadas três charges de um site especializado, 
de domínio público, com temática relacionada ao meio ambiente.

Além do critério da temática, outro utilizado para a seleção do corpus foi a presença de elementos verbais e imagéticos, já que esses dois modos semióticos auxiliam o leitor na construção de sentido. Para a análise, foram observadas algumas categorias da multimodalidade: a cor e saturação, a saliência, o olhar, o enquadramento, os elementos imagéticos representados e a relação entre texto verbal e imagem na construção do sentido da charge. A integração entre algumas dessas categorias analisadas é grande e por isso, nas charges aqui apresentadas, não houve como separá-las em linhas bem definidas. Vale ressaltar que os títulos colocados nas charges selecionadas abaixo estão presentes no próprio site.

Figura 1 - Charge "O lixo".

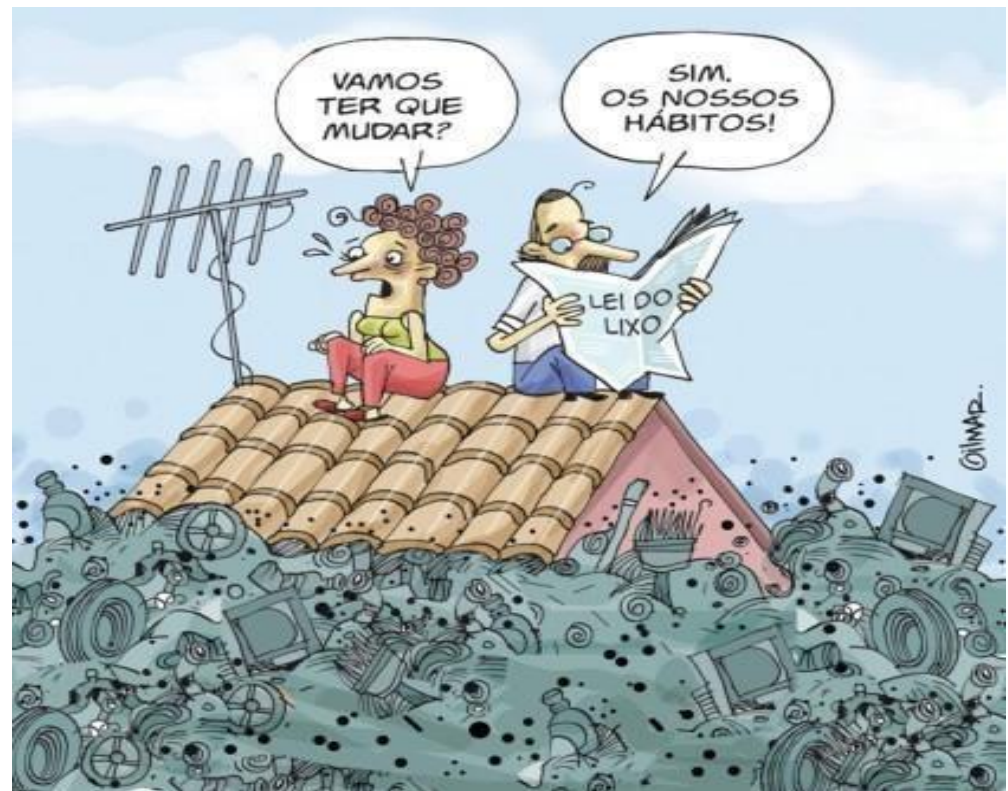

Fonte: Gilmar Machado (2018).

A figura 1 aborda a temática da questão do lixo no Brasil. Os elementos representados e a disposição deles fazem uma alusão aos alagamentos que assolam algumas regiões do país. Mas nesse caso o "alagamento" é de lixo. Os elementos imagéticos representados são o casal, o céu, parte da casa e o lixo. Esses elementos juntos transmitem a mensagem e a reflexão desejada para o tema abordado. A análise de cada um deles segue mais adiante.

Analisando o recurso multimodal "cor" verifica-se que o casal e a parte visível da casa estão em destaque (são os elementos salientes), por serem coloridos e se encontrarem no centro da imagem. O lixo está representado em cor cinza escura remetendo à poluição. Essa cor sugere também que a intenção não é destacar o que é descartado como lixo e sim a quantidade de lixo produzido e o perigo social que representa, podendo levar o leitor a refletir sobre a quantidade de lixo produzido por cada um, as ações de reciclagem, reutilização e o destino que é dado a ele. O sombreamento, existente ao fundo da imagem, na altura da casa e do lixo, (como em segundo plano) dá a ideia de continuidade do lixo, como se houvesse um mar de lixo, sendo um efeito buscado para a intenção de alertar para tal situação. 
Observando os demais elementos imagéticos verificamos que a mulher está sentada no telhado, em direção quase oposta ao marido, com os olhos arregalados, o olhar está voltado para a imensidão de lixo e com a boca aberta demonstrando uma expressão de espanto e susto pelo que vê. $\mathrm{O}$ homem, supomos que o marido da senhora, também sentado no telhado, mostra-se aparentemente calmo, seu rosto está parcialmente encoberto pelo jornal que tem em mãos e que parece ler, pois seus olhos estão direcionados a ele.

A linguagem verbal representada quando associada à imagem ajudam na construção de sentido do texto, dando o tom crítico e/ou irônico na charge. Nessa charge, a fala da mulher, com sugestão de uma atitude a ser tomada, está em contraposição à do homem, fato que provoca a ironia da charge. A esposa entende que, diante da situação em que se encontram, é necessário mudar de casa para fugir daquela situação e o homem, ao respondê-la, complementa a frase dita pela mulher fazendo um alerta. A mudança que deve ocorrer, de acordo com a proposta feita pelo homem, é uma mudança de atitude das pessoas em relação à questão do lixo, pois mudar de local não iria alterar o cenário em que se encontram.

O jornal apresenta como manchete principal a "lei do lixo" publicada em 2016, mesma data da publicação desta charge, que trata da coleta seletiva do lixo por parte de alguns órgãos e entidades nela elencados. Associando todos os elementos da imagem e a linguagem verbal presentes se reconhece e identifica um tom irônico e crítico. Não há como alcançar essa compreensão se analisar de modo separado a linguagem verbal da visual.

Figura 2 - Charge "Desmatamento".

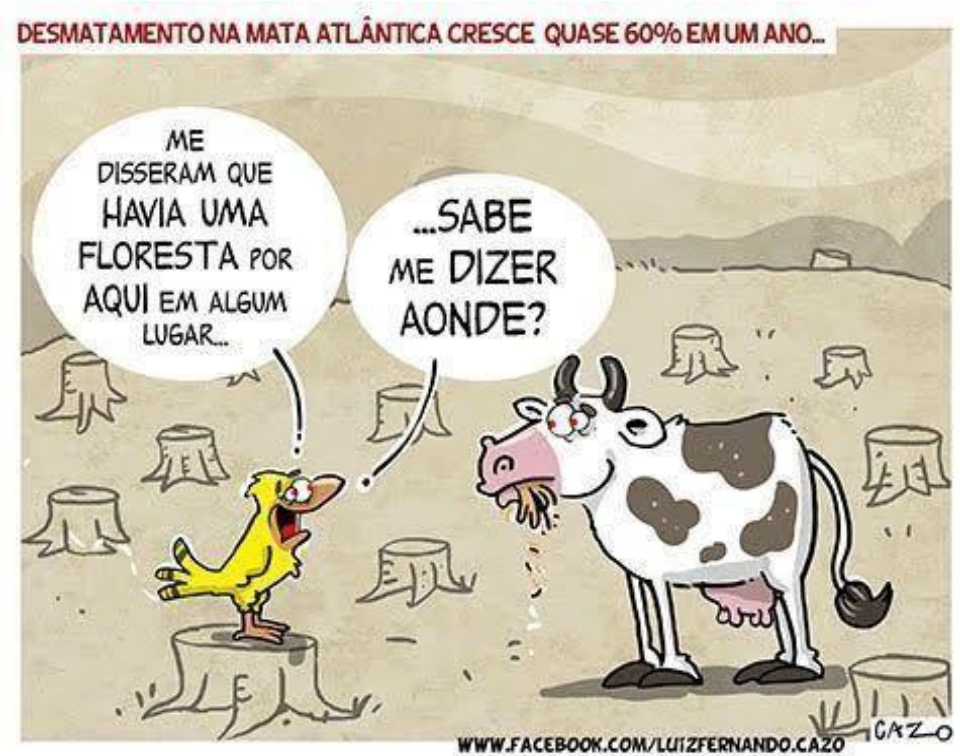

Fonte: Luiz Fernando Cazo (2017).

$\mathrm{Na}$ figura 2, ao observar os elementos imagéticos (pássaro, vaca e troncos de árvores) percebemos que se trata da questão do desmatamento. $O$ elemento que mais indica essa temática é a representação dos troncos cortados das árvores, que predominam na distribuição espacial.

São poucas as cores apresentadas nessa charge, sendo o elemento de maior 
destaque, o pássaro, por estar representado em um amarelo forte, cor natural de quem habita as matas, onde muitas cores vivas convivem. Por isso, ele chama atenção nessa imagem e contrasta com todo o restante do cenário que apresenta cores neutras e sem vida.

O pássaro está em busca de uma floresta, mas encontra um ambiente quase sem vida pela coloração meio cinza-amarelada e envelhecida do céu, dos troncos e da própria vegetação gramínea da qual deduzimos a existência por ser o alimento na boca da vaca. Essa coloração envelhecida também pode provocar uma sensação de tristeza e de solidão. Esse contraste de cores é um dos elementos que reforçam a crítica feita nessa charge sobre a questão do desmatamento para dar lugar a áreas de pastagens.

A noção da grande área devastada se percebe pela coloração usada nos troncos das árvores, na grama e no céu, porque sendo a mesma, dá ao leitor a noção de infinitude na devastação. Mesmo com a presença da linha que identifica a divisão entre a terra (área devastada) e o céu há uma igualdade entre eles, por estarem na mesma coloração, chegando a se confundirem, a darem uma ideia de continuidade.

Essa noção do tamanho da área devastada é dada tanto pela posição da linha que delimita o território, pois ela está mais acima na imagem, como pela presença do único tronco localizado além dessa linha divisória. Como não se pode ver a raiz desse tronco tocando o solo como nos demais troncos da imagem, a ideia repassada é a de que o desmatamento continua por uma área maior. Outro elemento que contribui com a ideia da extensão do desmatamento é o fato de não haver sombreamento de árvores ao fundo da imagem, dando a ideia de que sua ausência ocorre por uma longa extensão.

Além dos troncos das árvores, outros elementos imagéticos apresentados são o pássaro e a vaca, únicos animais presentes. Eles estão de frente um para o outro e o olhar de cada um se direciona ao outro, os olhos foram representados de forma que o leitor possa ter certeza da direção do olhar e da expressão atribuída a cada um. Os animais se apresentam mais próximos do leitor por se encontrarem mais próximos da borda inferior e são os elementos de destaque pela cor atribuída a eles em relação aos demais elementos da imagem.

Ao analisar a relação linguagem verbal-imagem, verificamos que a fala do pássaro está direcionada à vaca e mostra que ele está em busca de uma floresta localizada naquela região conforme lhe haviam dito. O mamífero reage com um olhar de estranheza demonstrando seu desconhecimento sobre o fato, pois o cenário que conhece é aquele em que se encontra. $\mathrm{Na}$ fala do pássaro destacam-se alguns termos em tamanho maior: "Havia uma floresta aqui" e "Sabe dizer aonde?". Esse destaque dá ênfase na busca do pássaro e na crítica da charge. O cenário, as expressões nos rostos dos animais e a fala do pássaro são os elementos que estabelecem a ironia no texto, levando o leitor à reflexão.

Outro elemento que contribui para a construção do sentido nessa charge é o título, identificado como um elemento intertextual, pois remete às notícias divulgadas na época de sua publicação sobre o aumento do desmatamento da Mata Atlântica. Para compreender essa situação se faz necessário que o leitor busque a informação nos textos jornalísticos, nos textos fonte, para resgatar ou conhecer os dados divulgados na época sobre o assunto e compreender mais profundamente o tema criticado na charge. 
Figura 3 - Charge "Dia Internacional do Meio Ambiente".

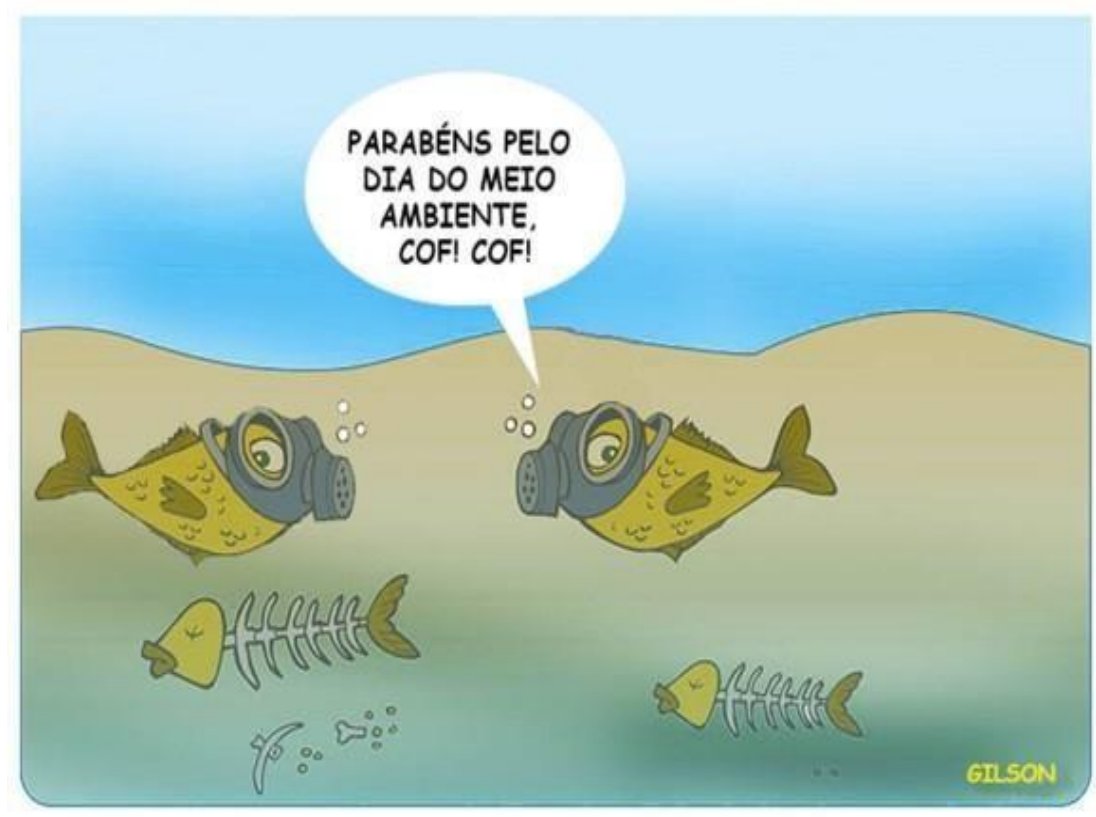

Fonte: Gilson Venancio Alvarenga (2017).

$\mathrm{Na}$ figura 3, percebe-se como conteúdo a poluição das águas. Os elementos imagéticos aqui representados são marcantes: os peixes vivos usando máscaras, a cor da água em contraste com a cor do céu e os esqueletos de peixe no fundo da água.

Em relação às cores, um ponto de destaque é a representação da cor da água e o contraste com a cor do céu. Esse está marcado por uma coloração azul, que é natural do elemento, e se distribui em degradê (diferentes graus de saturação), do mais claro até o azul mais escuro quando se encontra com água. A água está representada por uma coloração bege, envelhecida também em degradê, da mais clara até a mais escura no fundo, dando a ideia do mais raso ao mais profundo da água.

Essa coloração da água e a coloração amarelada (em grau de saturação mais elevado) dos peixes representam a poluição desse ambiente e a falta de vida nele, pois só há a presença de uns poucos peixes vivos que, para tentar continuar assim, utilizam máscaras antipoluição para respirar, não há nenhuma outra forma de vida típica do ambiente e alguns esqueletos de peixes no fundo da água, que pode representar o destino dos que ainda estão vivos.

A linha que divide a água e o céu está bem definida, delimitando bem esses dois ambientes. A cor da água leva um estranhamento inicial no leitor que espera que os peixes estejam em água de cor azul, como é comumente representada. E a presença do céu bem azul e água em cor bege, delimitados pela linha de separação, levam o leitor a refletir bem mais sobre a questão da poluição das águas, pois esse contraste leva o leitor, quase que obrigatoriamente, a essa reflexão.

Além dos elementos imagéticos já analisados temos os peixes vivos, que, mesmo usando máscaras antipoluição, encontram-se doentes, percepção possível pela coloração da pele e pela presença da onomatopéia “cof! cof?", que representa tosse, na fala de um dos peixes. O olhar dos peixes voltados para o leitor é um olhar que espera algo, alguma 
(re)ação para a situação em que eles se encontram. Essa imagem, mesmo sem analisar a linguagem verbal, já remete à crítica estabelecida na charge.

Já a ironia é marcada pelo contraste da fala do peixe "parabéns pelo dia do meio ambiente" com a representação do hábitat desse animal, bem como à data de sua publicação: dia 5 de junho, Dia Mundial do Meio Ambiente. Isso ressalta o alerta para o questionamento sobre o que comemorar realmente nesse dia, se o meio ambiente encontrase poluído e degradado. O efeito irônico só se estabelece nessa charge se a linguagem verbal não for separada da linguagem não verbal.

Nas charges aqui analisadas, destaca-se o papel fundamental dos dois modos presentes: o verbal e o imagético, que em conjunção, possibilitam a construção de sentido do texto e provocam o efeito irônico e crítico. Os elementos imagéticos permitem ao leitor antecipar o conteúdo da charge, pois "o leitor não aborda o texto como uma folha em branco" (ROJO, 2002, p. 5). Assim, o leitor relaciona seu conhecimento de mundo com o conhecimento exigido pelo autor.

Eles não são os únicos modos que participam desse processo: as cores, as linhas, a saliência, o plano, o cenário, as expressões, o contexto da charge e o conhecimento prévio do leitor também foram elementos que contribuíram. Sem deixar de mencionar a importância da intertextualidade, que possibilita a inferência realizada pelo leitor, ativando conhecimentos prévios.

\section{Considerações finais}

Com as análises realizadas percebemos que os elementos multimodais presentes em uma charge confluem para que o sentido seja produzido. Se isolados, cada um dos modos (o verbal e o não verbal) apresentaria um sentido particular que poderia ser diferente do sentido geral obtido ao analisar todos os modos da charge em conjunto.

A charge é um texto de ampla circulação, de fácil acesso e repleto de elementos que propiciam sua compreensão. Destacamos o papel dos elementos multimodais (imagens, as cores, o olhar, a fala e as saliências) que corroboram para a compreensão do leitor e desenvolvimento do seu senso crítico perante o que vê. A intertextualidade, quando presente, é outro elemento essencial para situar o leitor na construção do sentido, levandoo a ativar seu conhecimento prévio. Desconhecendo o fato representado, o leitor pode ir em busca do texto fonte para se inteirar do acontecimento, em busca de meios para atingir a compreensão.

A ativação do conhecimento de mundo do leitor é também essencial para que se alcance o sentido proposto pelo chargista, visto que a charge é elaborada com base em fatos sociais ou políticos ocorridos naquele momento. Essa ativação ocorre no primeiro momento pela observação dos elementos imagéticos representados, sendo confirmada depois em uma análise mais detalhada dos elementos ali presentes. Todos esses elementos mencionados são necessários para se atingir o efeito irônico e crítico da charge.

A interação do leitor com a charge e a compreensão da intenção do chargista, ao utilizar determinados elementos para representar uma crítica e emitir sua opinião sobre um tema atual, leva-nos a perceber a importância da análise dos recursos utilizados. Não lemos 
apenas a linguagem verbal, mas todos os recursos ou elementos semióticos presentes, pois cada um emite uma intenção que é captada pelos leitores. A leitura de um olhar ou de um contraste de cores conduz o pensamento dos leitores ao objetivo ali expresso. Nada está representado por acaso, tudo possui uma significação e a significação de um elemento complementa a do outro, conduzindo à compreensão geral.

\section{Referências}

BARBOSA, A.; SANTOS, M. S. L.; OLIVEIRA, E. M. Letramento multimodal e o texto em sala de aula nas séries iniciais do ensino fundamental. In: Anais da Jornada do Grupo de Estudos Linguísticos do Nordeste, 4 a 7 set. de 2012. Natal: EDUFRN, 2012. Disponível em: https://gelne.com.br/arquivos/anais/gelne-

2012/Arquivos/\%C3\%A1 reas \%20tem\%C3\%A1 ticas/Letramentos/Amanda $\% 20 \mathrm{e} \% 20 \mathrm{Mar}$ ia\%20-\%20LETRAMENTO\%20MULTIMODAL.pdf. Acesso em: 13 nov. 2019.

BARBOSA, V. S.; ARAÚJO, A. D.; ARAGÃO, C. O. Multimodalidade e multiletramentos: análise de atividades de leitura em meio digital. RBLA, Belo Horizonte, v. 16, n. 4, p. 623 $650,2016$.

CARVAlHO, D. A educação está no Gibi. Campinas: Papirus, 2006.

CASSANY, D. Prácticas letradas contemporáneas: claves para su desarrollo. Congreso Leer.es, Madrid, nov. 2003. Madrid: Ministerio de Educación, 2009.

CAVALCANTI, M. C. C. Multimodalidade e argumentação na charge. 2008. Dissertação (Mestrado em Letras) - Centro de Artes e Comunicação, Universidade Federal de Pernambuco, Recife, 2008.

COSCARELLI, C. V.; NOVAIS, A. E. Leitura: um processo cada vez mais complexo. Letras de Hoje, Porto Alegre, v. 45, n. 3, p. 35-42, jul./set. 2010.

DIONISIO, A. P. (Org.). Multimodalidades e leituras: funcionamento cognitivo, recursos semióticos, convenções visuais. Recife: Pipa comunicação, 2014.

FLÔRES, O. A leitura da charge. Canoas: Editora da Ulbra, 2002.

JEWITT, C. Multimodality, "reading", and "writing" for the 21st century. Discourse: studies in the cultural politics of education, New York, v. 26, n. 3, p. 315-331, set. 2005.

KRESS, G. Multimodality: a social semiotic approach to contemporary communication. New York: Routledge, 2010.

KRESS, G.; VAN LEEUWEN, T. Colour as a semiotic mode: notes for a grammar of colour. Visual Communication, v. 1, n. 3, p. 334-368, 2002. Disponível em: http://journals.sagepub.com/doi/abs/10.1177/147035720200100306. Acesso em: 28 nov. 2019.

KRESS, G.; VAN LEEUWEN, T. Reading images: the grammar of visual design. 2. ed. London: Routledge, 2006. 
ROJO, R. Letramento e capacidades de leitura para a cidadania. 2002. Disponível em: http://arquivos.info.ufrn.br/arquivos/2013121153a8f1155045828c12733b68e/Letramento _e_capacidade_de_leitura_pra_cidadania_2004.pdf. Acesso em: 28 nov. 2019.

VERGUEIRO, W.; RAMOS, P. (Org.). Quadrinhos na educação. São Paulo: Contexto, 2009. 